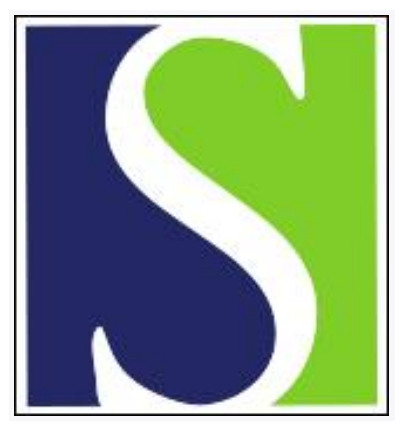

Scand J Work Environ Health 2009;35(3):188-192

https://doi.org/10.5271/sjweh.1320

Published online: 28 Apr 2009, Issue date: 00 May 2009

Work characteristics as predictors of physiological recovery on weekends

by Berset M, Semmer NK, Elfering A, Amstad FT, Jacobshagen N

Affiliation: Martial Berset, Department of Psychology, University of Bern, Muesmattstrasse 45, 3000 Bern 9, Switzerland. martial.berset@psy.unibe.ch

Refers to the following texts of the Journal: 2004;30(2):129-138

2000;26(4):306-316 2006;32(6):482-492

The following article refers to this text: 2013;39(3):310-318

Key terms: cortisol; job control; job demand; physiological recovery; stress; unwinding; weekend; work characteristic; work stress

This article in PubMed: www.ncbi.nlm.nih.gov/pubmed/19399350 


\title{
Work characteristics as predictors of physiological recovery on weekends
}

\author{
by Martial Berset, MSc, ${ }^{1,2}$ Norbert K Semmer, PhD, 1, 2 Achim Elfering, PhD, 1, 2 Fabienne T Amstad, \\ $P h D,{ }^{1,2}$ Nicola Jacobshagen, $P h D^{1,2}$
}

\begin{abstract}
Berset M, Semmer NK, Elfering A, Amstad FT, Jacobshagen N. Work characteristics as predictors of physiological recovery on weekends. Scand J Work Environ Health 2009;35(3):188-192.

Objectives This study investigated whether work characteristics predict physiological recovery on a rest day. Specifically, we aimed to show that high demands and low control at work would lead to higher cortisol values and thus poor recovery on a rest day.
\end{abstract}

Methods A total of 69 individuals participated in this study. In addition to analyzing questionnaire responses, we measured salivary cortisol on two workdays and on a subsequent rest day (a Sunday). We used multiple regression analysis. We controlled for the workday cortisol level; results reflect the relative change in cortisol from workday to rest day. In addition, we controlled for gender, since this relates to cortisol levels at work.

Results We found that control at the workplace predicted cortisol levels on a rest day. Specifically, individuals with less job control had higher cortisol levels, and consequently poorer recovery on the rest day than those with more control. Neither job demands nor the interaction of demands and control predicted a change in cortisol levels from workday to rest day.

Conclusions The results indicated that a lack of control at work impairs physiological recovery on the weekend, one of the central recuperation periods. In light of the potential importance of incomplete recovery with respect to long-term ill health, it should be considered crucial to ensure job control at the workplace.

Key terms cortisol; job demand; job control; stress; unwinding; work stress.

Recovery during non-working time from energy expenditure at work can be seen as a crucial link between acute reactions to stressful work characteristics and the development of ill health in the long run (1). It is therefore important to investigate variables that may affect recovery. Recovery can be seen as a "process of psychophysiological unwinding after effort expenditure" (p248, 1). It can take place at work during pauses (ie, internal recovery) and during non-working time, for instance in the evenings and on weekends [ie, external recovery (1)]. In this study, we focused on recovery on a rest day, specifically a Sunday.

Insufficient psychophysiological unwinding from work demands during rest periods implies a sustained overactivation of physiological stress systems that may become chronic in the long run. Researchers agree that such chronic overactivation can have severe consequences for health and wellbeing $(2,3)$. This process is theoretically well grounded in the Allostatic
Load Model (3) and the Effort-Recovery Model (4). The Allostatic Load model posits that the activation of physiological stress systems is functional when facing a stressful situation. However, parameters should drop to baseline levels once the stressful situation has passed. In others words, recovery should take place. If not, the overactivation can be become chronic (ie, an allostatic load), which could lead to several physiological and psychological impairments. The Effort-Recovery Model (4) puts forth a similar idea. It emphasizes that unless functional load reactions are followed by psychophysiological unwinding (ie, recovery), fatigue will accumulate and must be compensated with more effort. Again, in the long run, this may lead to a chronic load reaction and associated health problems.

Based on the assumption that psychophysiological unwinding should take place to achieve recovery, activation of the body's stress systems during recovery periods should indicate a lack of recovery. Cortisol is

1 Department of Psychology, University of Bern, Bern, Switzerland.

2 Swiss Center for Affective Sciences, Geneva, Switzerland.

Correspondence to: Martial Berset, Department of Psychology, University of Bern, Muesmattstrasse 45, 3000 Bern 9, Switzerland. [E-mail: martial.berset@psy.unibe.ch] 
one of the main stress hormones. Like other stress indicators, it should increase in active phases - and, indeed, there is some research indicating that cortisol levels are higher at work $(5,6)$ - but it should decrease in times of recovery. Assuming that the weekend is typically a time of recovery (7), lower cortisol levels on weekends, versus workdays, should indicate recovery.

Demands and control are the main variables of the Job Demands-Control Model (8). Excessive demands at work can impair unwinding in several ways. First, they can imply prolonged working hours, with the consequence that time for recovery may be too short to fully recover. Second, high demands increase the need for recovery (4), implying that recovery requires more time, which may often not be available. Third, high demands may induce cognitive preoccupation with stress-related issues (ie, rumination), which prolongs the stress reaction and, therefore, impedes recovery [the so-called concept of "perseverative cognitions" (9)]. In a similar vein, lack of job control may also lead to more rumination during free time. This was shown by Grebner et al (10) who found that low job control was related to an "inability to switch off after work" - a measure closely related to rumination. Furthermore, better job control may provide workers the opportunity to create mini-breaks at work, during which recovery could take place. Also, job control allows them to schedule their tasks in an efficient way with respect to their resources, which should then lead to a lower need for recovery after work and on weekends (1). Other researchers argue that humans have an intrinsic need for control (11). Not having enough control would, therefore, be a threat to that need and experienced as stressful.

The empirical evidence for the Job DemandsControl model in general is quite strong for the negative effects of high demands and low control. The postulated interaction between job demands and control has, however, found only modest support (12).

Concerning variables indicating recovery, Sluiter et al (13) showed that both high demands and a lack of decision latitude at work independently increased the need for recovery. In addition, Rau (14) showed that, compared to a low-strain group, women in a high-strain group had higher systolic and diastolic blood pressure shortly after going to sleep, and higher systolic blood pressure during the night. Men had higher systolic and diastolic blood pressure during leisure time when they were in the high-strain group. These results indicate incomplete recovery of the high-strain group.

With respect to cortisol, several studies have investigated the effect of stressors on waking cortisol or aggregated measures. Field studies using cortisol measures during recovery as a dependent variable are less frequent, and results are mixed (15-18). Fox et al (19) presented supporting results. The contact time of nurses with their patients and its interaction with job control predicted cortisol levels at home. With regard to experimental investigations, Dickerson \& Kemeny (20) showed in a meta-analysis that "uncontrollability" emerged as one of two stressful task characteristics (the second one being social-evaluative elements) that were especially predictive of both the level and duration of cortisol responses.

Overall, existing results are mixed and clearly require further research on the role of job demands and control in predicting recovery, especially for responses that are not based on questionnaires but on independent measures, such as cortisol. We analyzed cortisol on a Sunday with job demands and control as predictors. We controlled for cortisol levels during work, implying that the dependent variable reflects a relative change in cortisol from work to rest day. A higher level of cortisol on the rest day was, therefore, interpreted as an indication of poor recovery.

We hypothesized that high job demands hinder while control facilitates recovery. Because of the modest empirical support for the interaction between job demands and control in general (12), we did not formulate an interaction hypothesis.

\section{Study population and methods}

\section{Participants and design}

We invited employees from three departments of a large Swiss service provider to participate in our study. The sample included blue- and white-collar workers who were not in supervisory positions. Of the 85 participants (approximately $65 \%$ of the total eligible number), 16 were excluded for the following reasons: (i) no provision of cortisol measures (5), (ii) currently on medication (9), or (iii) an outlier on the cortisol measure, $(z \geq 3,2)$. The resulting sample consisted of 69 participants ( 30 women and 39 men). The age of participants varied between 16 and 61 years; the mean age was 37.96 years (standard deviation 11.15).

\section{Measures}

Job demands were assessed with an index of taskrelated stressors, based on the Instrument for Stress Oriented Task Analysis (21). The index consisted of five different task stressors containing four items each: (i) time pressure, (ii) concentration demands, (iii) performance constraints, (iv) uncertainty, and (v) work interruptions. Participants rated each item on a 5-point Likert scale. Scores on the scale reflected the frequency of certain situations, for example "How often do you experience time pressure?". The range was "very rarely" (1) to "very often" (5). The exception was the stressor 
"performance constraints", where two workplaces with opposing characteristics were described (for example "(a) must spend a lot of time in order to get information and/or materials to pursue his/her work activity" versus "(b) always has the necessary information and/ or materials at his/her disposal"). Participants had to rate how close their own workplace was to (a) versus (b); 1 = exactly like (a), 3 = between (a) and (b), $5=$ exactly like (b). Items were re-coded in such a way that high values reflected a high level of the stressor.

The five scales correlated with each other, but they were not expected to represent a homogenous construct. The appropriate measure of reliability therefore was not coefficient alpha, but the composite score proposed by Nunnally \& Bernstein (22). Its value was $r_{Y Y}=0.86$.

Control was measured with a 6-item scale covering time control and method control with three items each [5-point Likert scale and Instrument for Stress Oriented Task Analysis (21)]. Internal consistency was $\alpha=0.87$.

A number of control variables might be correlated with job control, demands, or cortisol. Among them are age, gender, and level of education. In order to keep predictors in the regression analysis to a reasonable number, we included control variables only if they were associated with job demands, control, or cortisol (either at work or on a rest day). Because age and level of education were not associated with these variables but gender was, we only included gender as a control variable in the regression analysis.

We measured salivary cortisol on two work days and on a Sunday by having participants chew on a cotton cylinder. We took all measures at noon. The unit of measurement for cortisol concentration was nanomole per liter. We averaged the two workday measures. Individuals were instructed to refrain from eating, drinking (except water), brushing their teeth, and smoking one hour before the measurement and, on the rest day, from physical activity and heavy domestic work. Individuals were asked to indicate how much time they spent on domestic work, childcare, work, and sports during a Sunday morning. None of those activities were correlated with cortisol at noon in this study. Therefore, we did not include them in our analyses.

\section{Statistics}

Using job demands and control at work as predictors, and controlling for gender and cortisol on work days, we analyzed data using multiple regression analysis. We entered all variables simultaneously. In order to allow for a better interpretation of regression coefficients representing interactions, we centered job control and demands at their mean (23). The cortisol level recorded on the Sunday was the dependent variable.

\section{Results}

Descriptives and correlations are displayed in table 1. Women have higher cortisol than men on workdays $(\mathrm{r}=0.24, \mathrm{P}<0.05)$, but not on rest days. Job control shows no bivariate association with cortisol levels on either a work or rest day. Job demands, however, are negatively associated with workday cortisol $(\mathrm{r}=-0.38$, $\mathrm{P}<0.01)$.

The results of the regression analysis are displayed in table 2 . Job control $(\beta=-0.25, \mathrm{P}=0.04)$ and workday cortisol $(\beta=0.345, P=0.010)$ were the only significant predictors. Job demands failed to explain the variance in the cortisol level on a rest day. In a similar vein, gender did not contribute to cortisol variance on a rest day. Although we had not predicted it, we tested the interaction between job demands and control, as it is an important part of the Job Demands-Control model. As expected, however, the interaction was not significant $(\mathrm{P}=0.827)$.

Table 1. Descriptives and Pearson correlations.

\begin{tabular}{|c|c|c|c|c|c|c|c|}
\hline \multirow[b]{3}{*}{ Gender $(\mathrm{N}=69)^{\mathrm{a}}$} & \multirow{3}{*}{$\begin{array}{c}\text { Mean } \\
0.57\end{array}$} & \multirow{3}{*}{$\begin{array}{c}\text { SD } \\
0.50\end{array}$} & \multirow{3}{*}{$\begin{array}{c}\text { Range } \\
0-1\end{array}$} & \multirow{3}{*}{$\begin{array}{c}\text { Gender }^{\mathrm{a}} \\
. .\end{array}$} & \multicolumn{2}{|c|}{ Cortisol } & \multirow[t]{2}{*}{ Control } \\
\hline & & & & & \multicolumn{2}{|c|}{ Work Rest } & \\
\hline & & & & & .. & .. & .. \\
\hline \multicolumn{8}{|l|}{ Cortisol (N=69) } \\
\hline Work & $3.70^{b}$ & 2.50 & $0.8-11$ & $0.24^{c}$ & .. & .. & .. \\
\hline Rest & $3.41^{b}$ & 2.59 & $0-10.7$ & 0.09 & $0.29^{c}$ & .. & .. \\
\hline Control $(\mathrm{N}=69)$ & 3.01 & 0.88 & $1-4.8$ & 0.07 & 0.03 & -0.21 & .. \\
\hline Demands $(\mathrm{N}=68)$ & 2.99 & 0.49 & $1.7-4.1$ & -0.07 & $-0.38^{d}$ & -0.05 & 0.19 \\
\hline
\end{tabular}

Table 2. Regression analysis predicting cortisol on a rest day with demands and control. Note: $R^{2}=0.162$. $(B=$ unstandardized regression coefficient, $\mathrm{SE} B=$ standard error, $\beta=$ standardized regression coefficient)

\begin{tabular}{lcccc}
\hline Variable & B & SE B & $\beta$ & P-value \\
\hline Cortisol (work) (N=69) & 0.357 & 0.134 & 0.345 & 0.010 \\
Gender a (N=69) & 0.150 & 0.621 & 0.029 & 0.810 \\
Control (N=69) & -0.734 & 0.350 & -0.250 & 0.040 \\
Demands (N=68) & 0.708 & 0.685 & 0.133 & 0.305 \\
\hline
\end{tabular}

a $0=$ male, 1 = female. Pairwise deletion . 


\section{Discussion}

Based on theoretical assumptions, we postulated that work characteristics affect recovery. Our indicator of recovery was the cortisol level on a rest day, controlling for cortisol on workdays.

Our assumptions were partly confirmed. Our findings supported the hypothesis that job control facilitates recovery (ie, an effect of control) but did not support the postulation that job demands hinder recovery (ie, an effect of demands). Lack of job control has been shown to have a main effect on various outcomes many times $(24,25)$. It seems likely that there is a basic need for job control (11), which implies that a lack of such control is likely to be stressful regardless of job demands.

Given the many findings that show the effects of job demands on strain (12) and recovery (26), it is difficult to explain the lack of effect of such demands on cortisol levels on a rest day. We therefore tested several possibilities that might account for this result. First, we wanted to rule out that one of the specific stressors contained in the demand index showed an effect that may have been covered by the other stressors. This was, however, not the case. Second, the effect of demands might show at very high levels only, implying a nonlinear association. We tested such a nonlinear association (more specifically, a quadratic effect), but could not confirm it.

The negative correlation between job demands and workday cortisol levels is somewhat surprising and counterintuitive. We do not have an explanation for this effect and hope that further research will shed light on it. Note, however, that a recent review of field studies involving mental demands and cortisol concluded that the results were inconsistent (27). Our results concerning the variables of the Job Demands-Control model are in line with evidence that control is a more consistent predictor of health than demands, as shown in the Whitehall-Study $(24,25)$.

As expected, we did not find an interaction between job demands and control. We tested this interaction by using a multiplicative term, because we believe this to be the appropriate way to test the hypothesis that the effect of one variable, for example demands, depends on the level of another one, in this case control (23). We also tested the ratio of demands to control as a predictor, but no effect emerged. Another possible explanation is a three-way interaction. Based on the same data set as the current analyses, but using dependent variables assessed by self-report, Meier et al (28) found the interaction postulated by the Job-Demands Control model to apply only for people high in personal resources (ie, internal locus of control and, partly, selfefficacy). We therefore tested this three-way interaction with regard to relative changes in cortisol levels, but again the findings were insignificant.

Our study had several limitations. First, the sample size was quite small. Second, due to resource constraints, only one cortisol measure could be sampled per day and per individual, which might be an issue with respect to the reliability of the measure. We decided to collect the samples at noon because we wanted to measure cortisol during the workday and not after work. This procedure had a further important advantage. We were able to visit the participants at their workplace, coach them in using the cotton cylinders, and take the samples with us to freeze them. It is our experience that participants appreciate both the effort and the contact involved, and that fewer problems with attrition and missing data arise if we proceed that way. Third, there is a possibility that individuals with low job control wake up later on Sunday mornings and that this might have affected the measurement of cortisol levels at noon. As part of the general instructions, we asked the participants to get up at about the same time on Sunday as during the work week. Unfortunately, we did not assess awakening time and, therefore, cannot be certain that they did, indeed, comply with this request. Fourth, our results indicated that individuals with low control show a lack of physiological recovery on Sundays. It would have been interesting to know if the same effect would have emerged with more subjective measures, such as the need for recovery, or fatigue. Unfortunately we did not assess such data on the rest day. In sum, we recommend replicating our study using several cortisol measures per day and assessing subjective fatigue. Furthermore, samples that are larger and include different working populations should be investigated in order to ensure replication and enhance generalization.

Despite these limitations, we believe that our results are relevant. In line with other findings in the literature, they clearly underscored the importance of job control for parameters related to health $(24,25)$. In addition, however, they added to the literature by showing an effect of job control on physiological recovery - a mechanism that is likely to be of pivotal importance for the "transmission" of stress experiences into longterm health consequences. Furthermore, we used a physiological parameter that is well established in its importance in the stress process and that is not subject to common method variance. Our results, therefore, add to the growing evidence that providing employees with improved job control is one of the most important means of creating healthier workplaces, and that recovery processes may constitute a crucial link between short- and long-term consequences of working conditions with regard to health. 


\section{References}

1. Geurts SAE, Sonnentag S. Recovery as an explanatory mechanism in the relation between acute stress reactions and chronic health impairment. Scand J Work Environ Health. 2006;32(6):482-92.

2. Kivimäki M, Leino-Arjas P, Kaila-Kangas L, Luukkonen R, Vahtera J, Elovainio M, et al. Is incomplete recovery from work a risk marker of cardiovascular death? Prospective evidence from industrial employees. Psychosom Med. 2006;68(3):402-7.

3. McEwen BS. Protective and damaging effects of stress mediators. N Engl J Med. 1998;338(3):171-9.

4. Meijman TF, Mulder G. Psychological aspects of workload. In: Drenth PJD, Thierry H, De Wolff CJ, editors. Handbook of work and organizational psychology. Hove (England): Psychology Press/Erlbaum; 1998. p 5-33.

5. Sluiter JK, Frings-Dresen MHW, van der Beek AJ, Meijman TF, Heisterkamp SH. Neuroendocrine reactivity and recovery from work with different physical and mental demands. Scand J Work Environ Health. 2000;26(4):306-16.

6. Sluiter JK, van der Beek AJ, Frings-Dresen MH. Work stress and recovery measured by urinary catecholamines and cortisol excretion in long distance coach drivers. Occup Environ Med. 1998;55(6):407-13.

7. Eden D. Job stress and respite relief: overcoming high-tech tethers. In: Perrewé PL, Ganster DC, editors. Research in occupational stress and well-being: exploring theoretical mechanisms and perspectives. Oxford: Elsevier; 2001. p 143-94.

8. Karasek Jr RA. Job demands, job decision latitude, and mental strain: Implications for job redesign. Admin Sci Q. 1979;24(2):285-308.

9. Brosschot JF, Pieper S, Thayer JF. Expanding stress theory: prolonged activation and perseverative cognition. Psychoneuroendocrino. 2005;30(10):1043-9.

10. Grebner S, Semmer NK, Elfering A. Working conditions and three types of well-being: a longitudinal study with self-report and rating data. J Occup Health Psychol. 2005;10(1):31-43.

11. Frese M. Theoretical models of control and health. In: Sauter SL, Hurrell Jr JJ, Cooper CL, editors. Job control and worker health. Chichester (England): John Wiley \& Sons Ltd; 1989. p 108-28.

12. De Lange AH, Taris TW, Kompier MAJ, Houtman ILD, Bongers PM. "The very best of the millennium": longitudinal research and the demand-control-(support) model. J Occup Health Psychol. 2003;8(4):282-305.

13. Sluiter JK, de Croon EM, Meijman TF, Frings-Dresen MHW. Need for recovery from work related fatigue and its role in the development and prediction of subjective health complaints. Occup Environ Med. 2003;60(suppl 1):62-70.

14. Rau R. Job strain or healthy work: a question of task design. J Occup Health Psychol. 2004;9(4):322-38.
15. Steptoe A, Cropley M, Griffith J, Kirschbaum C. Job strain and anger expression predict early morning elevations in salivary cortisol. Psychosom Med. 2000;62(2):286-92.

16. Evans O, Steptoe A. Social support at work, heart rate, and cortisol: a self-monitoring study. J Occup Health Psychol. 2001;6(4):361-70.

17. Fujiwara K, Tsukishima E, Kasai S, Masuchi A, Tsutsumi A, Kawakami N, et al. Urinary catecholamines and salivary cortisol on workdays and days off in relation to job strain among female health care providers. Scand J Work Environ Health. 2004;30(2):129-38.

18. Schnorpfeil P, Noll A, Schulze R, Ehlert U, Frey K, Fischer JE. Allostatic load and work conditions. Soc Sci Med. 2003;57(4):647-56.

19. Fox ML, Dwyer DJ, Ganster DC. Effects of stressful job demands and control on physiological and attitudinal outcomes in a hospital setting. Acad Manage J. 1993;36(2):289-318.

20. Dickerson SS, Kemeny ME. Acute stressors and cortisol responses: a theoretical integration and synthesis of laboratory research. Psychol Bull. 2004;130(3):355-91.

21. Semmer NK, Zapf D, Dunckel H. Assessing stress at work: a framework and an instrument. In: Svane O, Johansen C, editors. Work and health - scientific basis of progress in the working environment. Luxembourg: Office for Official Publications of the European Union; 1995. p 105-13.

22. Nunnally JC, Bernstein IRA. Psychometric theory. 3rd ed. New York (NY): Mcgraw Hill Book Co; 1994.

23 Aiken LS, West, SG. Multiple regression: testing and interpreting interactions. Newbury Park (CA): Sage; 1991.

24. Bosma H, Marmot MG, Hemingway H, Nicholson AC, Brunner E, Stansfeld SA. Low job control and risk of coronary heart disease in Whitehall II (prospective cohort) study. BMJ. 1997;314(7080):558-65.

25. Bosma H, Stansfeld SA, Marmot MG. Job control, personal characteristics, and heart disease. J Occup Health Psychol. 1998;3(4):402-9.

26. Sonnentag S, Fritz C. The recovery experience questionnaire: development and validation of a measure for assessing recuperation and unwinding from work. J Occup Health Psychol. 2007;12(3):204-21.

27. Hjortskov N, Garde AH, Ørbæk O, Hansen AM. Evaluation of salivary cortisol as a biomarker of self-reported mental stress in field studies. Stress Health. 2004;20(2):91-8.

28. Meier LL, Semmer NK, Elfering A, Jacobshagen N. The double meaning of control: three-way interactions between internal resources, job control, and stressors at work. J Occup Health Psychol. 2008;13(3):244-58.

Received for publication: 28 October 2008 